\title{
Jakinibs in Inflammatory Rheumatic Diseases. Clinical Perspective
}

José M. Serra López-Matencioa ${ }^{1}$, Concepción Martínez Nietoa ${ }^{1}$ and Santos Castañeda ${ }^{2^{*}}$

${ }^{1}$ Hospital Pharmacy Service, Hospital de la Princesa, IIS-Princesa, c/Diego de León 62, Madrid

${ }^{2}$ Rheumatology Division, Hospital de la Princesa, IIS-Princesa, c/ Diego de León 62, Madrid

*Corresponding author: Santos Castañeda, MD, PhD, Rheumatology Division, Hospital de la Princesa, IIS-Princesa, c/ Diego de León 62; 28006-Madrid, Tel: +34 91 520 2473; Fax: +34 91401 8752; E-mail: scastas@gmail.com; santos.castaneda@salud.madrid.org

Received date: June 20, 2018; Accepted date: June 21, 2018; Published date: June 26, 2018

Copyright: (c) 2018 López-Matencio JMS, et al. This is an open-access article distributed under the terms of the Creative Commons Attribution License, which permits unrestricted use, distribution, and reproduction in any medium, provided the original author and source are credited.

\section{Editorial}

Janus kinase (JAK) family represent an important group of cytoplasmatic kinases which are essential for the signalling pathways of multiple cytokines, growth factors and hormones involved in the pathogenesis of several autoimmune diseases [1]. These molecules consist of homodimer or heterodimer of JAK1, JAK2, JAK3 and TYK2. After the engagement of cytokines receptors constitutively bound to JAK, this is activated by a conformational change and later phosphorylated [2]. These in turn result in the phosphorylation of the signal transducers and activators of transcription (STAT) that subsequently translocate into the cell nucleus, where they regulate gene expression. Reflecting the involvement of multiple inflammatory cytokines in the pathological processes of rheumatoid arthritis (RA), both JAKs and STATs were increased in the synovium from patients with RA compared with osteoarthritis patients and the expression of JAK/STAT was diminished following treatment with conventional synthetic (cs) disease-modifying antirheumatic drugs (DMARDs) [3].

More than a decade ago, JAK/STAT signalling was described as one of the critical regulators of matrix metalloproteinase (MMP) gene expression [3]. Therefore, it will be important to determine the extent to which JAK alter MMP gene expression by chondrocytes, a major producer of MMPs in RA synovial joints. JAKs and TYK2 have also been involved in several phases of innate and adaptive immunity. In addition to the effect of JAK inhibitors on T-cell and B-cells, several JAK inhibitors have also been shown to alter the activity of osteoclasts and dendritic cells both of which are crucial to mediating bone erosions and antigen-presentation function, respectively [4].

Currently, numerous low molecular weight products targeting JAK are emerging for the therapy of several inflammatory diseases. These are small molecules available orally targeting specific kinase named as 'Jakinibs', and could represent a valuable tool associated to the csDMARDs and biological DMARDs in the available armamentarium for treating RA and other autoimmune diseases [5]. The development of tofacitinib is an example to encourage the translational research, throwing light upon basic research regarding intracellular signalling mechanisms and their relevance to pathological processes. The JAK3 inhibitors decernotinib and peficitinib showed strong and rapid efficacy and similar adverse events to tofacitinib in two phase 2 clinical trials. Furthermore, other two phase 2 trials were carried out with baricitinib targeting JAK1/2 and filgotinib targeting JAK1 with similar efficacy results [6].

Nevertheless, tofacitinib is associated with increased levels of lowdensity and high-density lipoprotein cholesterol as well as with reduced neutrophil counts. Thus, the extent to which 'Jakinibs' will either replace or supplement csDMARDs or biologic drugs as first-line therapies for RA still remains to be determined. Presently, moderate- to-severe RA continues to be treated with methotrexate plus/minus biological drugs [7]; the latter targeting either proinflammatory cytokines, TNF- $\alpha$, IL-6R or T-cell/B-cell proliferation, survival or biological activity. In addition, future studies should be conducted to ask what RA subgroups will get greater benefit from 'Jakinibs' compared with csDMARDs or biological agents [8].

Jakinibs have been used successfully in the treatment of several rheumatic diseases as a huge number of cytokines acts signalling through the JAK/STAT pathway. Nowadays, tofacitinib is the only Jakinib approved for autoimmune disease, although several more are about be launched on the drug market since several clinical trials are ongoing with various Jakinibs in several autoimmune conditions ranging from RA to psoriasis [9]. We think that, similarly, diseases characterized by serum elevations of JAK-dependent cytokines could respond well to Jakinibs therapy. These include diseases for which a type I IFN signature has been defined such as systemic lupus erythematosus, myositis, scleroderma, and primary Sjögren's syndrome, as well as diseases driven by IL-6 such as relapsing polychondritis and large-vessel vasculitis.

Interestingly, optimal doses and treatment strategy with Jakinibs is not well known yet. It is possible that loading patients with high doses to induce remission followed by a lower maintenance dose, would be an effective strategy, such as it is done with glucocorticoids [10]. Investigations of non-oral formulations of Jakinibs are also in the preliminary stages for diseases such as psoriasis, allergic dermatitis and ocular disease. Finally, biomarker development is ongoing to identify profiles of patients with diseases likely to respond to Jakinibs as complex rheumatic diseases may be driven by JAK-dependent cytokines to a different degree in different patients.

For all of this, we conclude that after the era of biologics, the development of Jakinibs and their successful use in autoimmune and inflammatory diseases represents an amazing new break-through in Rheumatology. These drugs are unique both structurally and functionally, as small molecules that can be administered orally, and which simultaneously block multiple cytokines.

In next years, Jakinibs are likely to change the field of autoimmune and rheumatologic diseases as clinical research will surely succeed improving selectivity, optimized dosing, formulation, and patient selection to minimize undesirable off-target effects and maximize clinical efficacy.

\section{Acknowledgements}

We want to express our gratitude to all the members of the Pharmacy and Rheumatology Divisions for their critical opinions and daily collaboration, and to Marysia $\mathrm{O}^{\prime}$ Driscoll for her support on English corrections. 
Citation: López-Matencio JMS, Nietoa CM, Castañeda S (2018) Jakinibs in Inflammatory Rheumatic Diseases. Clinical Perspective. J Arthritis 7: e119. doi:10.4172/2167-7921.1000e119

Page 2 of 2

\section{References}

1. O'Shea JJ, Gadina M, Kanno Y (2011) Cytokine signaling: birth of a pathway. J Immunol 187: 5475-5478.

2. Leonard WJ, O'Shea JJ (1998) Jaks and STATs: biological implications. Annu Rev Immunol 16: 293-322.

3. Russell SM, Tayebi N, Nakajima H, Riedy MC, Roberts JL, et al. (1995) Mutation of Jak3 in a patient with SCID: essential role of Jak3 in lymphoid development. Science 270: 797-800.

4. Leonard WJ, Noguchi M, Russell SM (1994) Sharing of a common gamma chain, gamma $c$, by the IL-2, IL-4, and IL-7 receptors: implications for X-linked severe combined immunodeficiency (XSCID). Adv Exp Med Biol 365: 225-232.

5. Kremer J, Li ZG, Hall S, Fleischmann R, Genovese M, et al. (2013) Tofacitinib in combination with nonbiologic disease-modifying antirheumatic drugs in patients with active rheumatoid arthritis: a randomized trial. Ann Intern Med 159: 253-261.

6. Tanaka Y, Emoto K, Cai Z, Aoki T, Schlichting D, et al. (2016) Efficacy and safety of baricitinib in Japanese patients with active rheumatoid arthritis receiving background methotrexate therapy: a 12-week, doubleblind, randomized placebo-controlled study. J Rheumatol 43: 504-511.

7. Ghoreschi K, Jesson MI, Li X, Lee JL, Ghosh S, et al. (2011) Modulation of innate and adaptive immune responses by tofacitinib (CP-690,550). J Immunol 186: 4234-4243.

8. Wollenhaupt J, Silverfield JC, Lee EB, Wood S, Soma K, et al. (2011) Tofacitinib (CP-690,550), an oral Janus kinase inhibitor, in the treatment of rheumatoid arthritis: open label, long-term extension studies up to 36 months. Arthritis Rheum 63: 161-162.

9. White JR, Phillips F, Monaghan T, Fateen W, Samuel S, et al. (2018) Review article: novel oral-targeted therapies in inflammatory bowel disease. Aliment Pharmacol Ther 47: 1610-1622.

10. Ludbrook VJ, Hicks KJ, Hanrott KE, Patel JS, Binks MH, et al. (2016) Investigation of selective JAK1 inhibitor GSK2586184 for the treatment of psoriasis in a randomized placebo-controlled phase $2 \mathrm{a}$ study. $\mathrm{Br} \mathrm{J}$ Dermatol 174: 985-895. 